\title{
Physico-chemical Modeling of Phase Separation in Fe-21.4 Cr Steel with 1.14 Mo Using the Provisions of Non-equilibrium Thermodynamics
}

\author{
Serhii V. Bobyr, Dmitro V. Loshkarev \\ Iron and Steel Institute of Z. I. Nekrasov NANU, Academic Starodubova Square, Dnipro, Ukraine
}

Email address:

svbobyr07@gmail.com (S. V. Bobyr)

\section{To cite this article:}

Serhii V. Bobyr, Dmitro V. Loshkarev. Physico-chemical Modeling of Phase Separation in Fe-21.4 Cr Steel with 1.14 Mo Using the Provisions of Non-equilibrium Thermodynamics. American Journal of Mechanical and Materials Engineering.

Vol. 5, No. 2, 2021, pp. 23-28. doi: 10.11648/j.ajmme.20210502.11

Received: May 18, 2021; Accepted: June 8, 2021; Published: June 21, 2021

\begin{abstract}
The use of ferritic-martensitic steels, for example, $\mathrm{Fe}-\mathrm{Cr}$ and $\mathrm{Fe}-\mathrm{Cr}-\mathrm{Al}$ alloys as structural material for fast neutron reactors has been advocated due to their relatively low rate of swelling at elevated temperatures. Because of the high $\mathrm{Cr}-$ content, the $\mathrm{Fe}-\mathrm{Cr}$ alloys are not suitable for use at temperatures around $500^{\circ} \mathrm{C}$ due to the miscibility gap in the $\mathrm{Fe}-\mathrm{Cr}$ system. Phase separation in such alloys can also be prevented by doping with elements that impede the segregation of chromium. In solid state physics for calculating phase separation in similar metal systems are used physicochemical and phase-field modeling. The aim of the work is the physicochemical modeling of diffusion phase transformation and determination of the long-term microstructural stability of the Fe-21.4 Cr-1.16 Mo. A conventional Fe-21.4 Cr alloy is used as a reference material. The article proposes an integral approach to modeling phase separation in chromium alloys, combining the determination of diffusion coefficients and fluxes of elements, taking into account their dependences on the concentration and an assessment of the mutual diffusion of elements, using the provisions of nonequilibrium thermodynamics. The calculated values of diffusion fluxes are used to calculate the current concentrations of carbon and chromium in the alloy and the size of chromium formations. They show that the thermal stability of the $\mathrm{Fe}-21.4 \% \mathrm{Cr}$ alloy with $1.16 \%$ Mo is much higher than without molybdenum. In alloy $\mathrm{Fe}-21,4 \% \mathrm{Cr}-1,16 \%$ Mo at a temperature of $973^{\circ} \mathrm{K}$, the chromium concentration during the same operation time decreases three times slower with the formation of inclusions of the $\sigma$-phase about 6 microns in size.
\end{abstract}

Keywords: Physicochemical Modeling, Phase Transformation, Fluxes, Chromium Alloys, Nonequilibrium, Thermodynamics, Diffusion Coefficients

\section{Introduction}

The use of ferritic-martensitic steels as structural material for fast neutron reactors has been advocated due to their relatively low rate of swelling at elevated temperatures, for example, Fe-Cr and Fe-Cr-Al alloys [1-12]. Fe-Cr-Al alloys have lately been proposed as candidate materials for use in various reactor systems, such as the lead cooled fast reactor (LFR) and light water rectors (LWR), due to the ability to form thin, slow growing and corrosion resistant alumina layers on their surfaces [4-12]. Historically, the same alloys have mainly been used as resistance heating elements at temperatures up to about $1300^{\circ} \mathrm{C}$ [13]. The composition is typically around $20 \mathrm{wt} . \% \mathrm{Cr}$ and $5 \mathrm{wt} . \% \mathrm{Al}$, with a base of $\mathrm{Fe}$.
Because of the high Cr-content, the alloys are not suitable for use at temperatures around $500^{\circ} \mathrm{C}$ as the microstructure decomposes into a Fe-rich $(\alpha)$ phase and a Cr-rich $\left(\alpha^{\prime}\right)$ phase due to the miscibility gap in the $\mathrm{Fe}-\mathrm{Cr}$ system [14-19]. This type of phase separation is commonly known as $475^{\circ} \mathrm{C}$ embrittlement or $\alpha-\alpha^{\prime}$ phase separation. Because of the embrittlement, such alloys are impracticable for use as structural components. The aforementioned power systems all need alloys that can operate in the temperature interval between $300^{\circ} \mathrm{C}$ and $700^{\circ} \mathrm{C}$ (or higher). However, due to the phase separation issue, conventional $\mathrm{Fe}-\mathrm{Cr}-\mathrm{Al}$ alloys are not realistic alternatives. By lowering the $\mathrm{Cr}$-content of the alloy, the phase separation issue could theoretically be avoided as the phenomenon is governed by the total $\mathrm{Cr}$-content in the 
ferritic matrix. In literature, phase separation in $\mathrm{Fe}-\mathrm{Cr}-\mathrm{Al}$ has been experimentally studied for a wide range of compositions During the 1960's, Fe-Cr-Al alloys were extensively studied for use in nuclear applications. Based on hardness measurements, it was proposed that the $\mathrm{Cr}$ limit to avoid $\alpha-\alpha^{\prime}$ phase separation was somewhere in the interval of 10 to 15 wt.\%, for a Fe-Cr-4Al alloy [19]. In a more recent study, Kobayashi et al. [20] studied various $\mathrm{Fe}-\mathrm{Cr}-\mathrm{Al}$ alloys, aged at $475^{\circ} \mathrm{C}$ for $1000 \mathrm{~h}$. The study resulted in a ternary phase diagram, indicating compositional limits for $\alpha-\alpha^{\prime}$ phase separation.

In article [21], Fe-10Cr-XAl $(\mathrm{X}=4,6$ and 8) alloys and a $\mathrm{Fe}-21 \mathrm{Cr}-5 \mathrm{Al}$ were thermally aged in the temperature interval of 450-550 $\mathrm{WC}$ for times up to $10,000 \mathrm{~h}$, and the microstructures were evaluated mainly using atom probe tomography. In addition, a kinetic Monte Carlo (KMC) model of the Fe-Cr-Al system was developed. No phase separation was observed in the Fe-10Cr-XAl alloys, and the developed KMC model yielded results in good agreement with the experimental data.

Phase separation in such alloys can also be prevented by doping with elements that impede the segregation of chromium. To quantify the effect of elements on phase separation, multi-scale modeling is required. The numerical tools that are applied include ab initio solutions to the Schroodinger equation, fitting of effective many-body interaction potentials, molecular dynamics simulation of recoil cascades, Monte Carlo simulation of defect evolution and quasicontinuum rate theory [22, 23]. The formation energy and other thermodynamic properties of monocrystalline $\mathrm{Fe}-\mathrm{Cr}$ in the ferromagnetic phase is difficult to measure, and hence one has to rely on theoretical approaches. In [22] was described from first principle calculations of thermodynamic and magnetic properties. Special attention is devoted to $\mathrm{Cr}$ concentrations below $15 \%$, being of relevance for materials actually used in reactors.

In solid state physics, other methods for calculating phase separation in similar metal systems - physicochemical and phase-field modeling [24-27] are well known and described in detail. Of considerable interest is the use of these methods for the analysis of promising alloys and steels in nuclear energy.

The aim of the work presented here is the physicochemical modeling of diffusion phase transformation and determination of the long-term microstructural stability of the Fe-21.4 Cr-1.16 Mo alloy. As a reference material, the usual alloy $\mathrm{Fe}-21.4 \mathrm{Cr}$ is used. It should be noted, that experimental data describing the main diffusion parameters of $\mathrm{Fe}-\mathrm{Cr}$ alloys for potential calculations, are not always available. In our case, there are experimental data for the diffusion coefficients of $\mathrm{Fe}-\mathrm{Cr}$ alloys with different $\mathrm{Cr}$ contents. However, these data were practically not used to calculate phase separation in such alloys. Therefore, our modeling approach combines the determination of diffusion coefficients and fluxes taking into account their concentration dependences, estimation of the mutual diffusion of elements using the provisions of nonequilibrium thermodynamics, and the use of diffusion flux values to calculate the current concentration of chromium in the alloy and the sizes of chromium formations.

\section{Materials and Research Methods}

As materials for research in this work, we used alloys with the composition $\mathrm{Fe}-21.4 \% \mathrm{Cr}$ and $\mathrm{Fe}-21.4 \% \mathrm{Cr}-1.16 \%$ Mo and known diffusion coefficients at different temperatures [27]. In accordance with the phase diagram [28] and the results of $[22,23]$, in the $\mathrm{Fe}-21.4 \% \mathrm{Cr}$ alloy at elevated temperatures, a chromium-rich $\sigma$-phase is formed, the composition of which was considered constant and equal to $\mathrm{FeCr}$. For the $\mathrm{Fe}-21.4 \% \mathrm{Cr}-1.16 \% \mathrm{Mo}$ alloy, the composition of the resulting phase $\mathrm{FeCr}-1.16 \%$ Mo was adopted, i.e. assumed that molybdenum is distributed uniformly in this alloy without forming segregations. For the $\sigma$-phase, the diffusion mechanism of its formation was adopted in this work. Consequently, during the diffusion of chromium, its concentration in the solid solution of the alloy changes and the diffusion coefficients of chromium and iron change. To take into account the change in the values of the diffusion coefficients from the chromium content, two reference alloys with a low chromium content were used - Fe - $16.1 \% \mathrm{Cr}$ and $\mathrm{Fe}-16.1 \% \mathrm{Cr}-1.16 \% \mathrm{Mo}$, also with known diffusion coefficients at different temperatures [27]. The equations for the change in the diffusion parameters with a decrease in the chromium concentration in the solid solution at each time point were found from the linear equations 1 and 2, respectively:

$$
\begin{aligned}
\mathrm{D}_{\mathrm{Cr}}^{\mathrm{i}} & =\mathrm{D}_{\mathrm{Cr}}^{0}+\alpha_{\mathrm{Cr}} *\left(0.214-\mathrm{C}_{\mathrm{Cr}}^{\mathrm{i}}\right), \\
\mathrm{D}_{\mathrm{Fe}}^{\mathrm{i}} & =\mathrm{D}_{\mathrm{Fe}}^{0}+\alpha_{\mathrm{Fe}} *\left(0.214-\mathrm{C}_{\mathrm{Cr}}^{\mathrm{i}}\right),
\end{aligned}
$$

where $\alpha_{C r}$ and $\alpha_{F e}$ - corresponding calculated coefficients.

To find the parameters of the equation for the diffusion coefficient:

$$
\mathrm{D}=\mathrm{A}_{0} \exp \left(-\mathrm{U}_{0} / \mathrm{RT}\right)
$$

used the values of the diffusion coefficients $D_{1}$ and $D_{2}$ for chromium (and iron) at two boundary temperatures $T_{1}$ and $T_{2}$ :

$$
\begin{gathered}
U_{0}=\frac{R\left(L n D_{1}-L n D_{2}\right)}{T_{2}^{-1}-T_{1}^{-1}}, \\
A_{0}=\exp \left(-L n D_{1}+U_{0} / R T_{1}\right) .
\end{gathered}
$$

The fluxes of chromium and iron in our system were found from the equations of nonequilibrium thermodynamics [29]:

$$
\begin{gathered}
\mathrm{J}_{\mathrm{Cr}}=\mathrm{L}_{11} \mathrm{X}_{\mathrm{Cr}}+\mathrm{L}_{12} \mathrm{X}_{\mathrm{Fe}} \\
\mathrm{J}_{\mathrm{Fe}}=\mathrm{L}_{21} \mathrm{X}_{\mathrm{Cr}}+\mathrm{L}_{22} \mathrm{X}_{\mathrm{Fe}}
\end{gathered}
$$

where $L_{11}=\left(C_{C r}^{i} * D_{C r}^{i}\right) / R T, L_{22}=\left(C_{F e}^{i} * D_{F e}^{i}\right) / R T$ [29], $L_{12}=\operatorname{sqrt}\left(L_{11} * L_{22}\right)$ [30], $C_{C r}^{i}$ and $C_{F e}^{i}$ - current concentrations of chromium and iron in the alloy.

The thermodynamic forces of chromium and iron for our discontinuous system were found by the formulas $[28,30]$ : 


$$
\begin{aligned}
& \mathrm{X}_{\mathrm{Cr}}=\mathrm{RT} \ln \left(\mathrm{C}_{\mathrm{Cr}}^{\mathrm{i}} / \mathrm{Ck}_{\mathrm{Cr}}\right), \\
& \mathrm{X}_{\mathrm{Fe}}=\mathrm{RT} \ln \left(\mathrm{C}_{\mathrm{Fe}}^{\mathrm{i}} / \mathrm{Ck}_{\mathrm{Fe}}\right),
\end{aligned}
$$

where $C k_{C r}=0.06$ - concentration of chromium in an alloy at which phase separation does not occur [22], $C k_{F e}=1$ $C k_{C r}$.

As can be seen from formulas (8), (9), the thermodynamic force for chromium has a positive sign, and for iron it has a negative sign, i.e. directed in the direction opposite to the iron flow. Therefore, the diffusion of chromium in the alloy is leading, and the diffusion of iron is forced, i.e. slave. In accordance with equation (4.1), the thermodynamic force of iron decreases the magnitude of the diffusion flux of chromium. To assess the mutual influence of the elements, we also calculated the comparative fluxes of chromium and iron without cross-linking, $J_{C r}^{0}=L_{11} X_{C r} J_{F e}^{0}=L_{22} X_{F e}$, and the corresponding current concentrations of chromium and iron $C^{0 i}{ }_{C r}$ and $C^{0 i}{ }_{F e}$.

Changes in the concentrations of chromium and iron over time were found by numerically integrating the system of continuity equations [29]:

$$
\begin{gathered}
\frac{\partial C_{C r}}{\partial t}=K_{m} J_{C r} / \Delta x, \\
\frac{\partial C_{F e}}{\partial t}=K_{m} J_{F e} / \Delta x,
\end{gathered}
$$

the concentration values were recalculated from $\mathrm{mol} / \mathrm{cm}^{3}$ units to atomic fractions through constant conversion coefficients $K_{m}$.

The system of differential equations $(10,11)$ allows us to find changes in concentrations and fluxes over time.

The average radius of the formed particles of the $\sigma$-phase was estimated by the expression given in [30]:

$$
R_{C r}^{2}=K \int_{0}^{i} J_{C r} d t
$$

where $K$ - coefficient equal to the ratio of the mass of the formed particles to the mass of the diffused element, in this case chromium.

Substituting equation (10) into expression (12) and expanding the integral, we find the formula for calculating the average size (diameter) of the formed particles of the $\sigma$ phase at time $t i$ :

$$
d_{C r}^{i}=2 \Delta x \sqrt{\frac{K\left(C_{C r}^{0}-C_{C r}^{i}\right)}{K_{m}}} .
$$

where $C_{C r}^{0}$ - initial concentration of chromium in the alloy;

$C_{C r}^{i}$ - the current concentration of chromium in the solid solution at time $\mathrm{i}$;

$\Delta \mathrm{x}$ - the minimum distance of diffusion of chromium in the alloy.

\section{Research Results}

Iron-chromium-aluminum (Fe-Cr-Al) alloys have been widely studied as candidate materials for various nuclear applications [4-21]. Despite their excellent corrosion resistance, $\mathrm{Fe}-\mathrm{Cr}-\mathrm{Al}$ alloys suffer from phase separation and embrittlement when exposed to temperatures up to $500^{\circ} \mathrm{C}$ due to their high $\mathrm{Cr}$ content. It can be assumed that alloys with a low $\mathrm{Cr}$ content but containing $\mathrm{Al}$ are also unstable to phase separation and brittleness. As the double diagram of the Fe-Al system shows, in such alloys, even with an insignificant $\mathrm{Al}$ content, a brittle phase of the $\mathrm{Fe}_{3} \mathrm{Al}$ composition is formed, which has the same effect as the $\sigma$ phase in high-chromium alloys (Figure 1).

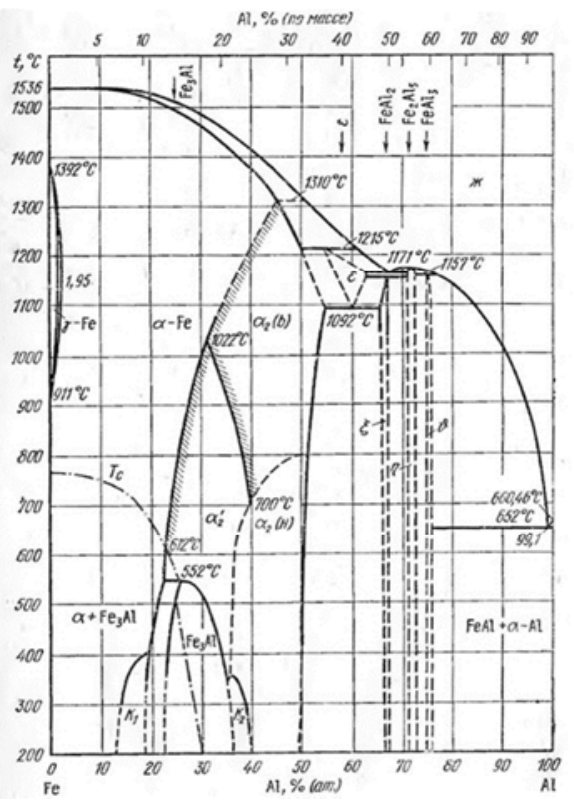

a

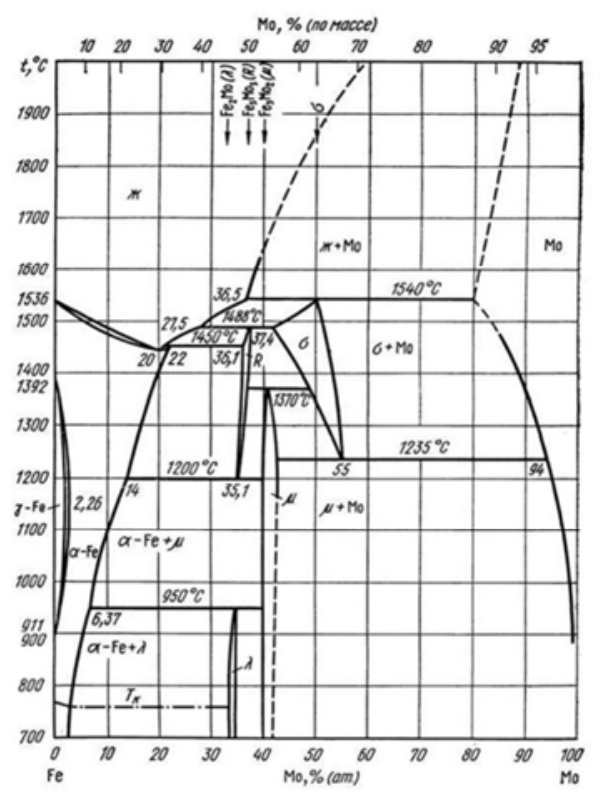

b

Figure 1. System state diagrams Fe-Al and Fe-Mo [27]. 
In addition, the diffusion of aluminum in iron occurs faster than chromium [27], which means that aluminum can significantly accelerate the embrittlement process in time.

To increase corrosion resistance, you can use alloys with a higher concentration of chromium, but containing elements that prevent its segregation. Molybdenum can be considered as a candidate for alloying. Molybdenum not only strengthens the $\alpha$-solid solution, but also contributes to an increase in its viscosity, preventing high-temperature embrittlement of alloys of the Fe-Cr system [31]. When its concentration in an alloy with $\mathrm{Fe}$ is less than 3.0 percent, it does not form any embrittlement phases with iron (Figure 1 b). Moreover, with chromium, molybdenum forms a solid solution without forming brittle phases [32].

In this work, the object of research is $\mathrm{Fe}-(16.1-21.4) \% \mathrm{Cr}$ alloys with $1.16 \%$ Mo in comparison with $\mathrm{Fe}-(16.1-21.4) \%$ $\mathrm{Cr}$ alloys. The chromium content in the alloys exceeds $15 \%$, ensuring their high corrosion and heat resistance [24]. The diffusion coefficients for these alloys at different temperatures are known in the literature [27]. The parameters of the Arrhenius equation for the diffusion of iron and chromium in the studied alloys calculated by formulas (3.1, 3.2) are given in Table 1.

Table 1. The parameters of the Arrhenius equation for the diffusion of iron and chromium in the studied alloys.

\begin{tabular}{|c|c|c|c|c|}
\hline \multirow{2}{*}{ Alloy composition } & Parameters & of the diffusion of chromium & Parameters & of the iron diffusion \\
\hline & $A_{0}, \mathbf{m}^{2} / \mathbf{s}$ & $\mathbf{U}_{\mathbf{0}}, \mathbf{J}$ & $\mathbf{A}_{0}, \mathrm{~m}^{2} / \mathrm{s}$ & $\mathbf{U}_{\mathbf{0}}, \mathbf{J}$ \\
\hline $\mathrm{Fe}-16,1 \% \mathrm{Cr}$ & $2,1 \quad 10^{-5}$ & 204232 & $10,6 \quad 10^{-5}$ & 234517 \\
\hline $\mathrm{Fe}-21,4 \% \mathrm{Cr}$ & $1,2 \quad 10^{-5}$ & 201008 & $14,0 \quad 10^{-5}$ & 238309 \\
\hline $\mathrm{Fe}-16,1 \% \mathrm{Cr}-1,16 \% \mathrm{Mo}$ & $20,9 \quad 10^{-5}$ & 232825 & $5,7 \quad 10^{-5}$ & 226905 \\
\hline $\mathrm{Fe}-21,4 \% \mathrm{Cr}-1,16 \% \mathrm{Mo}$ & $22,1 \quad 10^{-5}$ & 235484 & $12,6 \quad 10^{-5}$ & 237344 \\
\hline
\end{tabular}

It is already clear from these data that the diffusion of chromium has a high activation energy in alloys with molybdenum, i.e. diffusion of chromium occurs more slowly in the complex alloy. Direct calculations, of course, fully confirm this position. In this work, the current concentrations of chromium and iron in a solid solution were found by numerical integration of differential equations (10) and (11) at two temperatures - working $700^{\circ} \mathrm{K}$ and increased $-973^{\circ} \mathrm{K}$. The calculation results are shown in Figures 2 and 3 respectively.

They show that the thermal stability of the $\mathrm{Fe}-21.4 \% \mathrm{Cr}$ alloy with $1.16 \%$ Mo is much higher than without molybdenum. At an operating temperature of $700^{\circ} \mathrm{K}$, the concentration of chromium in the solid solution of the $\mathrm{Fe}$ $21.4 \% \mathrm{Cr}$ alloy decreases from $21.4 \%$ to $16.1 \%$ in about 70 years of operation, with the formation of $\sigma$-phase inclusions about 7 microns in size. In the $\mathrm{Fe}-21.4 \% \mathrm{Cr}-1.16 \% \mathrm{Mo}$ alloy, the chromium concentration changes insignificantly during the same operating time.

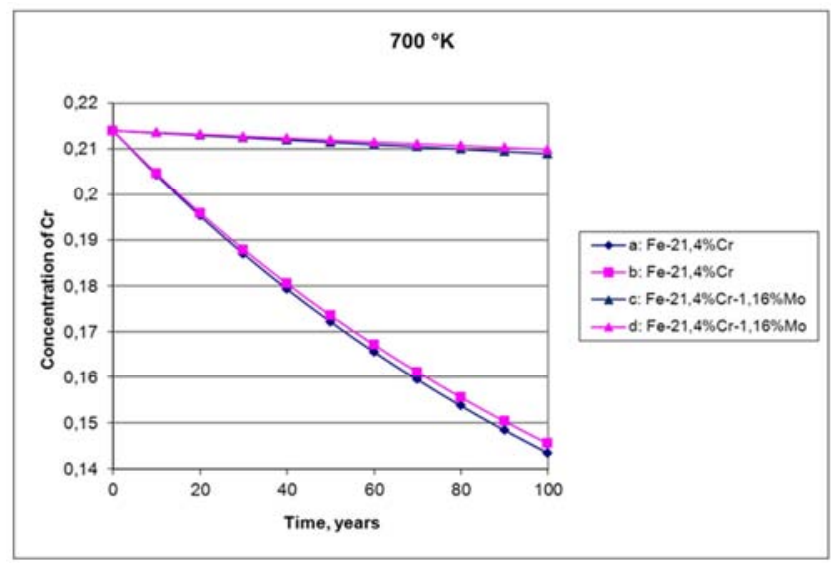

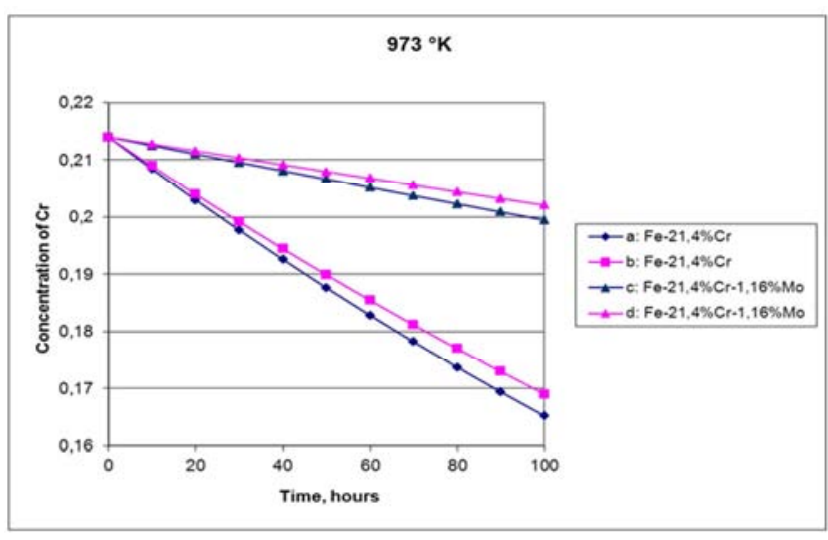

b

Figure 2. Change in chromium concentration in solid solution of steels $\mathrm{Fe}-$ $21,4 \% \mathrm{Cr}$ and $\mathrm{Fe}-21,4 \% \mathrm{Cr}-1,16 \% \mathrm{Mo}$ at a temperature $700 \mathrm{~K}(\mathrm{a})$ and $973^{\circ} \mathrm{K}(b)$, lines $a, c$ - without cross-links, lines $b, d$ - with cross-links.

At an elevated operating temperature of $973^{\circ} \mathrm{K}$, phase separation is observed in both alloys. The concentration of chromium in the solid solution of the $\mathrm{Fe}-21.4 \% \mathrm{Cr}$ alloy decreases from $21.4 \%$ to $16.1 \%$ in about 120 hours of operation, while inclusions of the $\sigma$-phase with a size of about 12 microns are formed.

In alloy $\mathrm{Fe}-21,4 \% \mathrm{Cr}-1,16 \%$ Mo at a temperature of $973^{\circ} \mathrm{K}$, the chromium concentration during the same operation time decreases three times slower with the formation of inclusions of the $\sigma$-phase about 6 microns in size. 


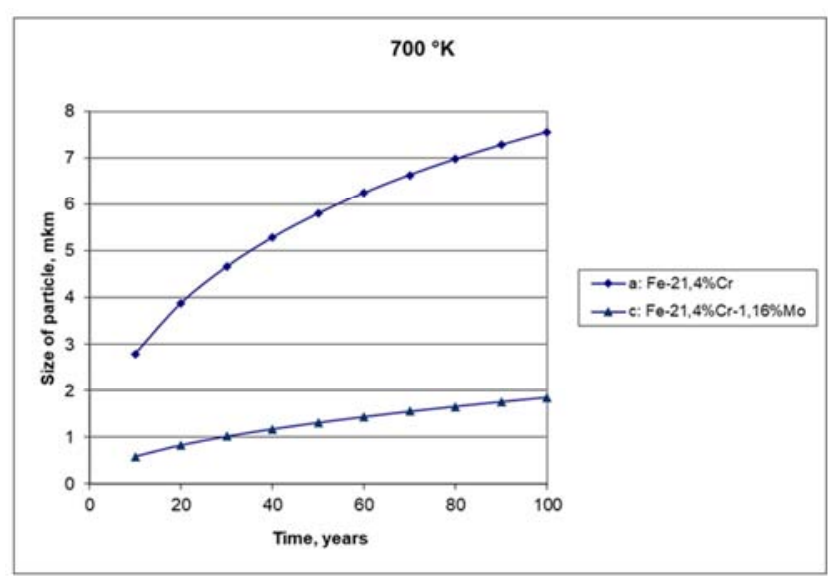

a

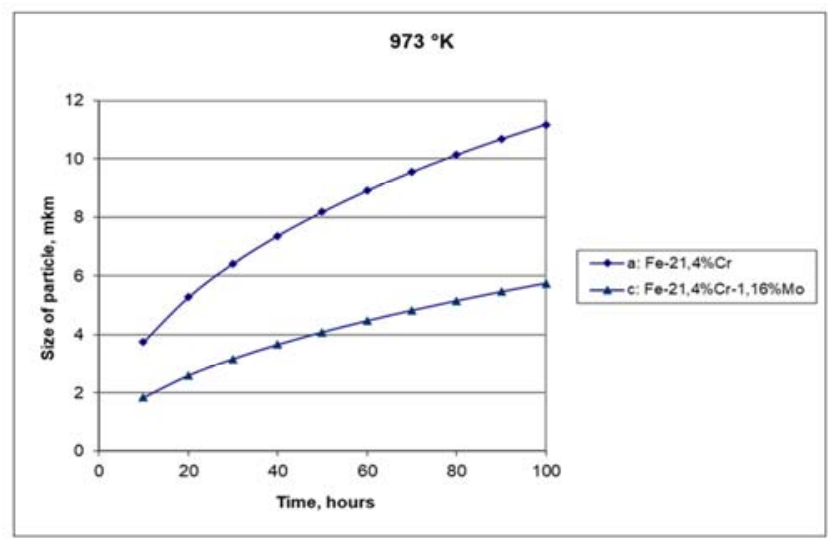

b

Figure 3. Changing the size of inclusions in steels $\mathrm{Fe}-21,4 \% \mathrm{Cr}$ and $\mathrm{Fe}-$ $21,4 \% \mathrm{Cr}-1,16 \% \mathrm{Mo}$ at a temperature $700^{\circ} \mathrm{K}($ a) u $973 \mathrm{~K}(\mathrm{~b})$.

\section{Conclusion}

Thus, in this work, it was assumed that alloys with a low $\mathrm{Cr}$ content but containing $\mathrm{Al}$ are unstable to phase separation and are prone to brittleness due to the formation of the $\mathrm{Fe}_{3} \mathrm{Al}$ phase and a high rate of aluminum diffusion in iron. The possibility of using alloys with an increased chromium content, but alloyed with molybdenum, in an amount of about $1.0 \%$, as a corrosion-resistant material for nuclear reactors is shown. Non-equilibrium thermodynamic modeling of diffusion phase transformation and determination of longterm microstructural stability of $\mathrm{Fe}-21.4 \mathrm{Cr}$ alloy with 1.16 Mo have been carried out. A conventional Fe-21.4 Cr alloy was used as a reference material.

The article proposes an integral approach to modeling phase separation in chromium alloys, combining the determination of diffusion coefficients and fluxes of elements, taking into account their dependences on the concentration and an assessment of the mutual diffusion of elements, using the provisions of nonequilibrium thermodynamics. The calculated values of diffusion fluxes are used to determine the current concentrations of iron and chromium in the alloy and the size of chromium formations.

If we compare the results obtained by the Monte Carlo method and nonequilibrium thermodynamic modeling, then the general estimate of the phase separation at different temperatures is similar. However, the approach using diffusion equations for elements in specific alloys, taking into account the dependences of the diffusion coefficients on concentration and their mutual influence, is more accurate and not just estimated. This approach allows us to calculate the change in the concentration of chromium in the solid solution and the size of the resulting inclusions of the $\sigma$ phase.

\section{References}

[1] E. A. Little, D. A. Stow, J. Nucl. Mater. 87 (1979) 25.

[2] D. S. Gelles, J. Nucl. Mater. 108\&109 (1982) 515.

[3] F. A. Garner, M. B. Toloczko, B. H. Sencer, J. Nucl. Mater. $276(2000) 123$.

[4] G. Muller, G. Schumacher, F. Zimmerman, J. Nucl. Mater., 278 (2000) 85-95.

[5] M. Kondo, M. Takahashi, J. Nucl. Mater., 356 (2006) 203-212.

[6] S. Takaya, T. Furukawa, K. Aoto, G. Muller, A. Weisenburger, A. Heinzel, M. Inoue, T. Okuda, F. Abe, S. Ohnuki, T. Fujisawa, A. Kimura, J. Nucl. Mater., 386 (2009) 507-510.

[7] J. Lim, H. O. Nam, I. S. Hwang, J. H. Kim, J. Nucl. Mater., 407 (2010) 205-210.

[8] M. Del Giacco, A. Weisenburger, A. Jianu, F. Lang, G. Mueller, J. Nucl. Mater., 421 (2012) 39-46.

[9] T. Cheng, J. R. Keiser, M. P. Brady, K. A. Terrani, B. A. Pint, J. Nucl. Mater., 427 (2012) 396-400.

[10] B. A. Pint, K. A. Terrani, M. P. Brady, T. Cheng, J. R. Keiser, J. Nucl. Mater., 440 (2013) 420-427.

[11] A. Weisenburger, A. Jianu, S. Doyle, M. Bruns, R. Fetzer, A. Heinzel, M. DelGiacco, W. An, G. Muller, J. Nucl. Mater., 437 (2013) 282-292.

[12] J. Ejenstam, M. Halvarsson, J. Weidow, B. Jönsson, P. Szakalos, J. Nucl. Mater., 443 (2013) 161-170.

[13] B. Jonsson, R. Berglund, J. Magnusson, P. Henning, M. Hattestrand, High Temperature Corrosion and Protection of Materials 6, Prt 1 and 2, Proceedings, 461-464 (2004) 455-462.

[14] R. O. Williams, H. W. Paxton, J Iron Steel Inst, 185 (1957) 358-374.

[15] R. Lagneborg, Acta Metall Mater, 15 (1967) 1737-1745.

[16] W. S. Spear, D. H. Polonis, Metall Mater Trans A, 25 (1994) 1135-1146.

[17] J. H. Lange, M. Brede, B. Fischer, S. Spindler, H. Wagner, R. Wittmann, D. Gerthsen, A. Broska, J. Wolff, MRS Online Proceedings Library, 539 (1998).

[18] C. Capdevila, M. K. Miller, K. F. Russell, J. Chao, J. L. Gonzalez-Carrasco, Mat Sci Eng a-Struct, 490 (2008) 277288. 
[19] C. Capdevila, M. K. Miller, K. F. Russell, J Mater Sci, 43 (2008) 3889-3893.

[20] S. Kobayashi, T. Takasugi, Scripta Mater, 63 (2010) 11041107.

[21] J. Ejenstam, M. Thuvander, P. Olsson, F. Rave, P. Szakalos. Microstructural stability of Fe-Cr-Al alloys at 450-500C. Journal of Nuclear Materials, 457 (2015) 291-297.

[22] J. Wallenius, P. Olsson, C. Lagerstedt, N. Sandberg, R. Chakarova, V. Pontikis. Modeling of chromium precipitation in Fe-Cr alloys, Phys. Rev. B 69 (9), 094103 (2004).

[23] P. Olsson, J. Wallenius, Ch. Domain, K. Nordlund, L. Malerba. Two-bond modeling of $\alpha$-prime phase formation in $\mathrm{Fe}-\mathrm{Cr}$. Phys. Rev., 72, 214119 (2005).

[24] S. Herzman and B. Sundman, "A thermodynamic analysis of the Fe-Cr system," Calphad, vol. 6, pp. 67-80, 1982.

[25] N. Lecoq, H. Zapolsky, \& P. Galenko, Evolution of the structure factor in spinodal decomposition. Eur. Phys. J. Spec. Top. 177, 165 (2009).
[26] J Boisse, N Lecoq, R Patte, H Zapolsky. Phase-field simulation of coarsening of $\gamma$ precipitates in an ordered $\gamma^{\prime}$ matrix. Acta Materialia 55 (18), 6151-6158.

[27] L. N. Larikov, V. I. Isajchev, Diffuziya v metallakh i splavakh. Spravochnik. (Kiev: Naukova dumka: 1987).

[28] O. A. Bannykh, P. B. Budberg, S. P. Alisova et al. State diagrams of binary and multicomponent systems based on iron. (Moskva: Metallurgiya, 1986).

[29] B. S. Bokshtejn, Diffuziya v metallakh (Moskva: Metallurgiya: 1978).

[30] S. V. Bobyr. Using the Principles of Nonequilibrium Thermodynamics for the Analysis of Phase Transformations in Iron-Carbon Alloys // chapter in book "Non-Equilibrium Particle Dynamics" - London Intechopen, May 2019, P. 95-140.

[31] L. I. Lysak, B. I. Nikolin Physical foundations of heat treatment of steel - Kiev: Technique, 1975-304p.

[32] V. N. Svechnikov, G. F. Kobzenko, "Chromium molybdenum state diagram", Dokl. USSR Academy of Sciences, 155: 3 (1964), P. 611-614. 